\title{
Desempenho animal e características de pastos de capim-piatã submetidos a diferentes intensidades de pastejo
}

\author{
Nayana Nazareth Nantes(1), Valéria Pacheco Batista Euclides(2), Denise Baptaglin Montagner ${ }^{(2)}$, \\ Beatriz Lempp ${ }^{(3)}$, Rodrigo Amorim Barbosa ${ }^{(2)}$ e Phillippe Oliveira de Gois ${ }^{(1)}$
}

\begin{abstract}
(1)Universidade Federal de Mato Grosso do Sul, Faculdade de Medicina Veterinária e Zootecnia, Cidade Universitária, s/no, Caixa Postal 549, CEP 79070-900 Campo Grande, MS. E-mail: nayzootecnia@hotmail.com, phillippe zootecnia@hotmail.com (2)Embrapa Gado de Corte, Avenida Rádio Maia, no 830, Zona Rural, CEP 79106-550 Campo Grande, MS. E-mail: valeria.pacheco@embrapa.br, demontagner@yahoo.com.br, rodrigo.barbosa@embrapa.br (3)Universidade Federal da Grande Dourados, Faculdade de Ciências Agrárias, Rodovia Dourados-Itahum, Km 12, Caixa Postal 322, CEP 79804-970 Dourados, MS. E-mail: beatrizlempp@ufgd.edu.br
\end{abstract}

Resumo - O objetivo deste trabalho foi avaliar o valor nutritivo, a estrutura do dossel e a produção animal de novilhos em pastos de capim-piatã (Urochloa brizantha, cultivar Piatã), manejados a 15, 30 e $45 \mathrm{~cm}$ de altura, sob lotação contínua. Utilizou-se o delineamento experimental de blocos ao acaso, com duas repetições e três alturas. As alturas dos pastos foram monitoradas duas vezes por semana, e as taxas de lotação ajustadas. Mensalmente, os pastos foram amostrados e os animais foram pesados. Não houve diferença no valor nutritivo dos pastos manejados com diferentes alturas. Os ganhos médios diários de $650 \mathrm{~g}$ por novilho foram semelhantes entre as diferentes alturas de manejo. A taxa de lotação foi menor para o pasto com $45 \mathrm{~cm}\left(2,4 \mathrm{UA} \mathrm{ha}^{-1}\right)$, intermediária para o de $30 \mathrm{~cm}\left(3,1 \mathrm{UA} \mathrm{ha}^{-1}\right)$ e maior para o manejado com $15 \mathrm{~cm}\left(3,8 \mathrm{UA} \mathrm{ha}^{-1}\right)$, o que resultou em maior ganho por área dos pastos manejados com $15 \mathrm{~cm}\left(1.050 \mathrm{~kg} \mathrm{ha}^{-1}\right)$ e $30 \mathrm{~cm}\left(910 \mathrm{~kg} \mathrm{ha}^{-1}\right)$ de altura, quando comparados ao manejado a $45 \mathrm{~cm}\left(635 \mathrm{~kg} \mathrm{ha}^{-1}\right)$. O capim-piatã apresenta grande flexibilidade de manejo sob lotação contínua e pode ser manejado entre 15 e $45 \mathrm{~cm}$ de altura.

Termos para indexação: Urochloa brizantha, Cerrado, estrutura do dossel, lotação contínua, taxa de lotação, valor nutritivo.

\section{Animal performance and sward characteristics of piatã palisade grass pastures subjected to different grazing intensities}

\begin{abstract}
The objective of this work was to evaluate the nutritive value, sward structure, and animal performance of steers on piatã palisade grass pastures (Urochloa brizantha, cultivar Piatã), managed at 15, 30, and $45 \mathrm{~cm}$ sward heights, under continuous stocking. A randomized block design, with two replicates and three sward heights, was used. Sward height was measured twice a week, and the stocking rate was adjusted. Monthly, the pastures were sampled and the animals were weighted. There was no difference in the nutritive value of the pastures managed with different heights. The average daily gain of $650 \mathrm{~g}$ per steer was similar among the different sward heights. The stocking rate was lower for the pasture managed at $45 \mathrm{~cm}\left(2.4 \mathrm{AU} \mathrm{ha}^{-1}\right)$, intermediary for the one with $30 \mathrm{~cm}\left(3.1 \mathrm{AU} \mathrm{ha}^{-1}\right)$, and higher for the one managed at $15 \mathrm{~cm}\left(3.8 \mathrm{AU} \mathrm{ha}^{-1}\right)$, resulting in greater gain per area for the pastures managed at a height of $15 \mathrm{~cm}\left(1,050 \mathrm{~kg} \mathrm{ha}^{-1}\right)$ and $30 \mathrm{~cm}\left(910 \mathrm{~kg} \mathrm{ha}^{-1}\right)$ than for the one managed at $45 \mathrm{~cm}\left(635 \mathrm{~kg} \mathrm{ha}^{-1}\right)$. Piatã palisade grass shows great flexibility under continuous stocking and can be managed between 15 and $45 \mathrm{~cm}$ sward height.
\end{abstract}

Index terms: Urochloa brizantha, savanna, sward structure, continuous stocking, stocking rate, nutritive value.

\section{Introdução}

A cultivar BRS Piatã de Urochloa brizantha (Syn. Brachiaria brizantha) apresenta boa adaptação aos solos de cerrados de média fertilidade, boa resposta à adubação, tolerância a fungos foliares e de raiz, florescimento precoce e, em janeiro e fevereiro, produz de 150 a $450 \mathrm{~kg} \mathrm{ha}^{-1}$ de sementes puras. Os ganhos de peso por animal e por área foram maiores do que aqueles obtidos em pasto de $U$. brizantha cultivar Marandu, tendo-se observado, em média, 610 e $560 \mathrm{~g}$ por dia e 705 e $660 \mathrm{~kg} \mathrm{ha}^{-1}$ de peso corporal (PC) por ano, para os capins piatã e marandu, respectivamente (Euclides et al., 2009). Essas características tornam a cultivar BRS Piatã excelente alternativa para a redução das extensas áreas caracterizadas por monocultivos de 
capim-marandu, hoje existentes em todos os estados das regiões Centro-Oeste e Sudeste.

A legislação vigente que regulamenta o lançamento de cultivares de plantas forrageiras, segundo portaria do Ministério da Agricultura, Pecuária e Abastecimento (Brasil, 2008), requer a apresentação de resultado referente ao valor de cultivo e uso (VCU) da cultivar a ser lançada. No entanto, esta exigência não assegura o uso adequado quando do lançamento de material novo. Portanto, há a necessidade de se desenvolver estudos para aprimorar o manejo do pastejo, com o intuito de otimizar o uso da forragem e o desempenho animal. De acordo com Euclides (2000), a simples substituição de forrageiras sem prática de manejo adequada não determina a melhoria na produtividade do sistema de produção. Da Silva \& Carvalho (2005) sugeriram que o baixo desempenho animal, em pastos tropicais, está associado à prática de manejo inadequado do pastejo.

Em um sistema pastoril, as respostas da planta e do animal são basicamente determinadas pela estrutura do dossel. Assim, o manejo dos pastos, fundamentado nas características estruturais das plantas que interagem com os fatores ambientais, tem-se mostrado mais eficiente na produção e na colheita da forragem produzida (Trindade et al., 2007; Difante et al., 2009). Neste contexto, Carnevalli et al. (2001a, 2001b), Flores et al. (2008) e Carloto et al. (2011) mostraram ser possível controlar a condição de pasto tropical, ao se ajustar o manejo do pastejo de acordo com a altura do pasto.

O objetivo deste trabalho foi avaliar o valor nutritivo, a estrutura do dossel e a produção animal de novilhos em pastos de capim-piatã (Urochloa brizantha) cultivar Piatã, manejados a 15, 30 e $45 \mathrm{~cm}$ de altura, sob lotação contínua.

\section{Material e Métodos}

O experimento foi realizado na Embrapa Gado de Corte, em Campo Grande, MS $\left(20^{\circ} 27^{\prime} \mathrm{S}\right.$ e $54^{\circ} 37^{\prime} \mathrm{W}$, a $530 \mathrm{~m}$ de altitude), de dezembro de 2008 a dezembro de 2009.

O clima da região, segundo a classificação de Köppen, é do tipo Aw, tropical chuvoso de savana. A precipitação média anual é de $1.560 \mathrm{~mm}$, e o período considerado de seca é de maio a setembro $(30 \%$ da precipitação anual). Durante o período experimental, a precipitação pluvial, a temperatura mínima, média e máxima mensal (Figura $1 \mathrm{~A}$ ) e a umidade relativa do ar foram registradas, e, para o cálculo do balanço hídrico, foram utilizadas a temperatura média e a precipitação mensal acumulada. A capacidade de armazenamento de água do solo (CAD) utilizada foi de $75 \mathrm{~mm}$ (Figura $1 \mathrm{~B}$ ).

O solo da área experimental é classificado como Latossolo Vermelho distrófico (Santos et al., 2006). Antes do estabelecimento dos pastos, o solo foi amostrado, na camada de $0-10 \mathrm{~cm}$, e a análise química indicou: $\mathrm{pH}$ em $\mathrm{CaCl}_{2}$ de 5,27; 55,77\% de saturação por bases; $0,84 \%$ de saturação por alumínio; $57,8 \mathrm{~g} \mathrm{~kg}^{-1}$ de matéria orgânica; 2,52 $\mathrm{mg} \mathrm{dm}^{-3}$ de P (Mehlich 1); e $79,11 \mathrm{mg} \mathrm{dm}^{-3}$ de K (Mehlich 1).
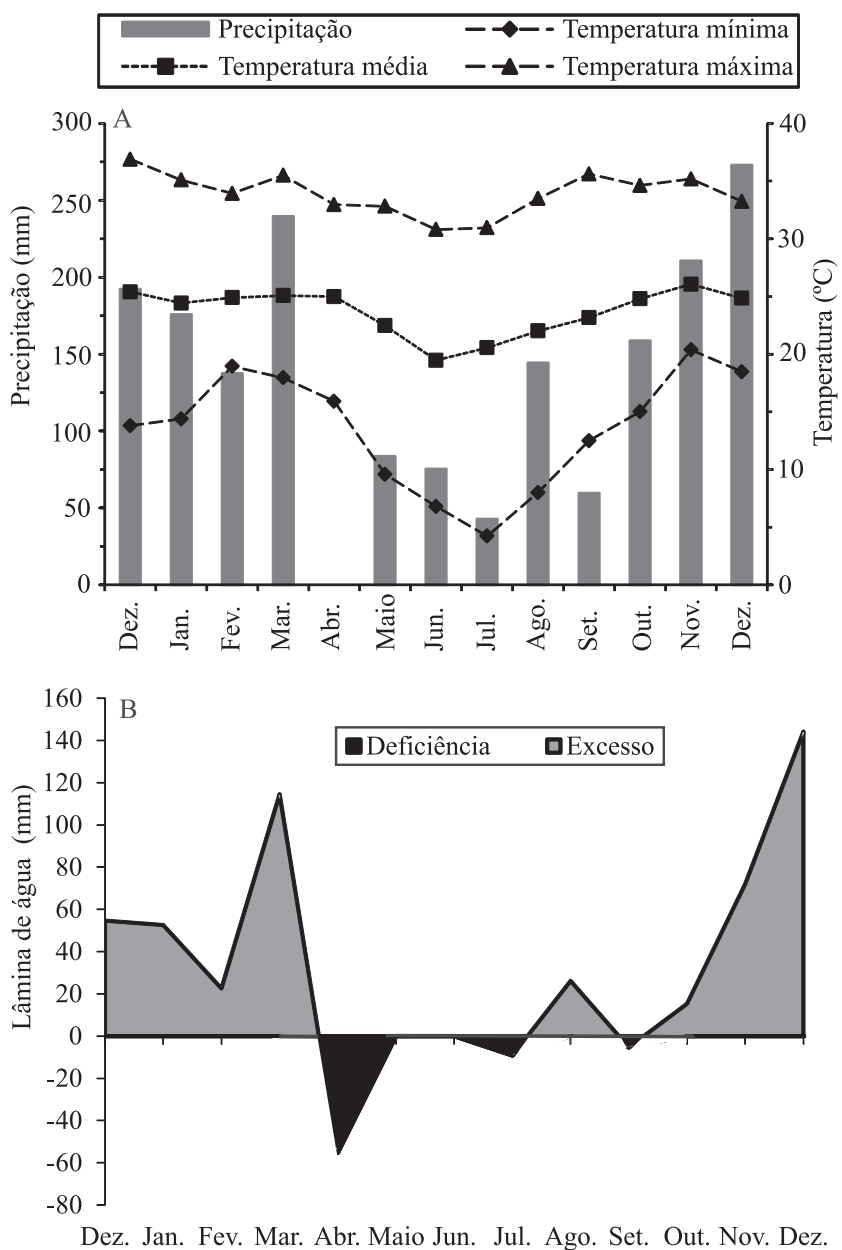

Figura 1. Precipitação pluvial, temperaturas máxima, média e mínima (A) e balanço hídrico mensal (B), durante o período de dezembro de 2008 a dezembro de 2009. 
Em novembro de 2007, a área experimental foi corrigida e adubada com $2,0 \mathrm{Mg} \mathrm{ha}^{-1}$ de calcário dolomítico (PRNT $=75 \%$ ), mais $80 \mathrm{~kg} \mathrm{ha}^{-1}$ de $\mathrm{P}_{2} \mathrm{O}_{5}, 80 \mathrm{~kg} \mathrm{ha}^{-1}$ de $\mathrm{K}_{2} \mathrm{O}$ e $32 \mathrm{~kg} \mathrm{ha}^{-1}$ de FTE BR-12. Os pastos de capim-piatã (U. brizantha) cultivar BRS Piatã, foram estabelecidos em janeiro de 2008. Foram semeados $2,2 \mathrm{~kg} \mathrm{ha}^{-1}$ de sementes puras viáveis do capim-piatã. Após a cobertura das sementes com passagem de grade niveladora fechada, procedeu-se à compactação do solo com rolo compactador. Em abril de 2008, foi realizado um pastejo leve; em julho, foi feita uma capina manual de invasoras; e, em outubro, foram construídas as cercas e instalados os bebedouros. Em novembro, iniciou-se o pastejo para gerar as alturas pretendidas dos pastos. As avaliações iniciaram-se a partir de 18/12/2008.

Foi realizada adubação nitrogenada de $90 \mathrm{~kg} \mathrm{ha}^{-1}$ de nitrogênio na forma de ureia, dividida em duas aplicações, em janeiro e fevereiro de 2009. Em outubro do mesmo ano, foi realizada adubação de manutenção, com $40 \mathrm{~kg} \mathrm{ha}^{-1}$ de $\mathrm{P}_{2} \mathrm{O}_{5}$ e de $\mathrm{K}_{2} \mathrm{O}$ da fórmula N-P-K $(0-20-20)$.

A área experimental foi dividida em seis piquetes de 0,67 ha, o que totalizou 4 ha. $\mathrm{O}$ método de pastejo foi o de lotação contínua, com taxa de lotação variável. Utilizou-se o delineamento experimental de blocos ao acaso, com três tratamentos e duas repetições. Os tratamentos foram constituídos pelas intensidades de pastejo representadas pelas alturas do dossel de 15 , 30 e $45 \mathrm{~cm}$.

O monitoramento das alturas dos pastos começou a ser feito em outubro de 2008, após as primeiras chuvas. Os animais foram adicionados aos piquetes à medida que as alturas dos pastos se tornaram próximas às metas dos tratamentos. Em meados de dezembro, todos os piquetes já se encontravam sob pastejo de todos os animais avaliadores, quando se iniciaram as avaliações.

Foram utilizados 50 novilhos Nelore, com idade média de 12 meses e peso inicial médio de $220 \mathrm{~kg}$. Destes, foram selecionados 18 animais que foram distribuídos nas unidades experimentais de forma que as médias de peso dos três animais, em cada piquete, foram praticamente as mesmas. Esses animais permaneceram no mesmo piquete, como animais avaliadores, até o final do período experimental. O restante do lote foi mantido no piquete reserva e utilizado como animais reguladores nas unidades experimentais sempre que houve necessidade de ajuste da taxa de lotação, para manter os pastos nas alturas pré-determinadas. Todos os animais receberam água e mistura mineral completa à vontade, além de manejo sanitário.

Mensalmente, todos os animais, avaliadores e reguladores, foram pesados após jejum de 16 horas. O ganho de peso médio diário foi calculado pela diferença de peso dos animais avaliadores, dividida pelo número de dias entre pesagens. A taxa de lotação mensal foi calculada como o produto do peso médio dos animais, avaliadores e reguladores, e do número de dias em que eles permaneceram nos piquetes, de acordo com Petersen \& Lucas Junior (1968). O ganho de peso animal por área foi obtido ao se multiplicar o ganho médio diário (GMD) dos animais avaliadores pelo número de animais (avaliadores e reguladores) mantidos por piquete e por mês.

Duas vezes por semana, a altura do pasto foi determinada em 60 pontos por piquete, distribuídos ao longo de quatro linhas com 15 pontos aleatórios em cada uma. A altura de cada ponto correspondeu à altura média do dossel em torno da régua.

A cada 28 dias, cortaram-se rente ao solo 15 amostras de forragem de $1 \mathrm{~m}^{2}$ por piquete, as quais foram divididas em duas subamostras: uma foi seca e pesada, e a outra foi separada em folha (lâmina foliar), colmo (colmo + bainha) e material morto; ambas foram secas e pesadas. A proporção de cada componente foi utilizada para estimar as relações folha:colmo (RFC) e folha:não folha (colmo + material morto; RFNF), e para as estimativas de massa de lâmina foliar. A densidade volumétrica de matéria seca foi calculada pela divisão da massa de matéria seca pela altura real do dossel.

Para a estimativa do crescimento da planta, foram utilizadas três gaiolas de exclusão de $1 \mathrm{~m}^{2}$ por piquete. A cada 28 dias, as gaiolas foram alocadas em pontos representativos da altura média do dossel, com massa e composição morfológicas semelhantes àquelas das áreas sob pastejo. A massa de forragem, dentro e fora da gaiola, foi obtida por corte ao nível do solo. Após cada corte, as gaiolas foram realocadas em outros pontos do piquete, seguindo a mesma metodologia. A taxa de crescimento da planta $\left(\mathrm{kg} \mathrm{ha}^{-1}\right.$ por dia de matéria seca) foi obtida por meio da diferença entre as massas de forragem observadas dentro (corte atual) e fora (corte anterior) da gaiola, dividida pelo número de dias entre as amostragens. Para a taxa de acúmulo de lâmina foliar, utilizou-se o mesmo procedimento, 
tendo-se considerado a proporção deste componente dentro e fora da gaiola.

A oferta de massa de matéria seca ( $\mathrm{kg}$ de matéria seca por $100 \mathrm{~kg}$ de peso vivo) foi calculada pela soma da massa de matéria seca presente no piquete e o crescimento da planta no período, dividida pelo total do peso vivo dos animais mantidos no piquete no mesmo período. A oferta de lâmina foliar ( $\mathrm{kg}$ de matéria seca de lâmina foliar por $100 \mathrm{~kg}$ de peso vivo) foi calculada da mesma forma, tendo-se considerado apenas esse componente da planta.

Mensalmente, em cada piquete, também foram coletadas, por dois amostradores, duas amostras simulando o pastejo animal, que foram secas e moídas a $1 \mathrm{~mm}$ e analisadas para estimar os teores de proteína bruta, fibra em detergente neutro, digestibilidade in vitro da matéria orgânica e lignina em detergente ácido. Utilizou-se o sistema de espectrofotometria de reflectância no infravermelho proximal (NIRS), de acordo com Marten et al. (1985).

Os dados referentes às características dos pastos foram agrupados por estações do ano da seguinte maneira: verão, de 18/12/2008 a 18/3/2009; outono, de 18/3/2009 a 23/4/2009; primavera, de 29/7/2009 a 17/12/2009.

Em virtude da redução da taxa de acúmulo de lâminas foliares durante maio e junho (Tabela 1), consequência do deficit hídrico (Figura $1 \mathrm{~B}$ ) e da pequena dimensão dos piquetes $(0,67$ ha), não foi possível manter os três animais avaliadores na área experimental e, ao mesmo tempo, manter as metas de altura do dossel (Tabela 1).

Tabela 1. Médias \pm desvios-padrão para taxa de acúmulo de folha (TAF) e alturas reais dos pastos de capim-piatã submetidos a três alturas de pastejo.

\begin{tabular}{lcccc}
\hline Meses & TAF & \multicolumn{3}{c}{ Altura do dossel (cm) } \\
\cline { 3 - 5 } & & 15 & 30 & 45 \\
\hline Dezembro & - & $16,8 \pm 0,7$ & $32,4 \pm 0,8$ & $46,8 \pm 0,5$ \\
Janeiro & $42,1 \pm 16,4$ & $16,2 \pm 0,3$ & $29,9 \pm 0,4$ & $44,7 \pm 1,5$ \\
Fevereiro & $50,9 \pm 10,6$ & $17,2 \pm 0,1$ & $30,4 \pm 1,6$ & $46,4 \pm 1,3$ \\
Março & $52,2 \pm 6,7$ & $14,8 \pm 0,6$ & $29,7 \pm 0,3$ & $43,8 \pm 0,4$ \\
Abril & $43,8 \pm 14,3$ & $14,2 \pm 0,2$ & $29,9 \pm 0,3$ & $43,2 \pm 0,4$ \\
Maio & $7,4 \pm 2,8$ & $13,8 \pm 0,4$ & $28,4 \pm 0,3$ & $42,8 \pm 0,2$ \\
Junho & $7,8 \pm 4,5$ & $16,1 \pm 1,4$ & $31,5 \pm 1,5$ & $43,1 \pm 0,5$ \\
Julho & $24,3 \pm 12,6$ & $16,2 \pm 0,7$ & $31,9 \pm 2,0$ & $42,6 \pm 1,6$ \\
Agosto & $11,9 \pm 5,4$ & $16,7 \pm 1,1$ & $31,0 \pm 0,9$ & $42,1 \pm 1,0$ \\
Setembro & $13,1 \pm 6,5$ & $14,8 \pm 0,4$ & $29,1 \pm 0,5$ & $44,4 \pm 1,7$ \\
Outubro & $11,8 \pm 6,5$ & $14,3 \pm 0,2$ & $28,4 \pm 0,4$ & $43,6 \pm 1,4$ \\
Novembro & $57,4 \pm 20,7$ & $16,6 \pm 0,7$ & $30,2 \pm 0,7$ & $45,7 \pm 1,0$ \\
Dezembro & $40,6 \pm 8,9$ & $16,0 \pm 1,0$ & $33,0 \pm 0,8$ & $47,2 \pm 0,9$ \\
\hline
\end{tabular}

Assim, optou-se pela retirada dos animais dos piquetes no período de 23/4/2009 a 14/7/2009. Como o período seco da região ocorre entre maio e setembro, o período das águas foi considerado de 18/12/2008 a 23/4/2009 e de 29/7/2009 a 17/12/2009.

Foi permitida uma amplitude de variação da altura dos pastos em torno da meta de $\pm 10 \%$. Durante o período das águas, as alturas permaneceram relativamente estáveis e dentro das amplitudes planejadas (Tabela 1).

Aanálise foi realizada com uso de modelo matemático contendo o efeito aleatório de bloco, e os efeitos fixos de altura do dossel e estações do ano, bem como suas respectivas interações. Já para a produção animal, utilizou-se análise multivariada com medidas repetidas segundo Littell et al. (1998). Para todas as análises, foi usado o procedimento Proc Mixed disponível no SAS Institute (1996). As médias foram comparadas pelo teste de Tukey, a $5 \%$ de probabilidade.

\section{Resultados e Discussão}

Não foi observada interação entre os efeitos de altura do dossel e de estação do ano para massas de matéria seca (MST; $p=0,1553$ ) e de folha (MSF; $\mathrm{p}=0,0666$ ); percentagens de folha $(\mathrm{PF} ; \mathrm{p}=0,1169)$ e de material morto (PM; $\mathrm{p}=0,0786)$; relações folha:colmo (RFC; $p=0,0749)$ e folha:não folha (RFNF; $p=0,2143$ ); e densidade volumétrica de matéria seca (DVMS; $\mathrm{p}=0,0979$ ). No entanto, houve interação entre altura do dossel e estação do ano para percentagem de colmo (PF; $p=0,0003$ ).

À medida que se aumentou a altura do dossel, houve acréscimos na MST e na MSF e decréscimo na DVMS (Tabela 2), o que confirma a relação positiva entre

Tabela 2. Médias, seus erros-padrão (EPM) e nível de significância (p) para massas de matéria seca (MST) e de folha (MSF), densidade volumétrica de matéria seca (DVMS), percentagem de colmo (PC) e relação folha:colmo (RFC), em pastos de capim-piatã submetidos a três alturas de pastejo $^{(1)}$.

\begin{tabular}{lccccc}
\hline Característica & \multicolumn{3}{c}{ Altura do dossel $(\mathrm{cm})$} & \multirow{2}{*}{ EPM } & $\mathrm{p}$ \\
\cline { 2 - 5 } & 15 & 30 & 45 & & \\
\hline MST (kg ha-1 de MS) & $2.010 \mathrm{c}$ & $3.270 \mathrm{~b}$ & $4.050 \mathrm{a}$ & 113 & 0,0001 \\
MSF (kg ha ${ }^{-1}$ de MS) & $600 \mathrm{~b}$ & $1.090 \mathrm{a}$ & $1.250 \mathrm{a}$ & 75 & 0,0001 \\
DVMS (kg ha-1 por cm de MS) & $128 \mathrm{a}$ & $108 \mathrm{~b}$ & $90 \mathrm{c}$ & 4,0 & 0,0001 \\
RFC & $1,3 \mathrm{a}$ & $1,4 \mathrm{a}$ & $1,0 \mathrm{~b}$ & 0,07 & 0,0019 \\
\hline (1)Médias seguidas de letras iguais não diferem pelo teste de Tukey, a 5\% \\
de probabilidade.
\end{tabular}


altura do dossel e massa de forragem encontrada para U. brizantha, cultivar Marandu (Calvano et al., 2011) e cultivar Xaraés (Carloto et al., 2011). Já a maior MSF em pastos manejados com menores intensidades de pastejo (30 e $45 \mathrm{~cm}$ ), foi consequência das maiores MST, uma vez que não houve diferença entre as diferentes alturas de manejo para PF $(p=0,1531$; média $=31,4 \pm 1,5 \%$ ).

Verificou-se padrão de variação semelhante, para a DVMS, para pastos dos capins xaraés e marandu manejados entre 15 e $45 \mathrm{~cm}$; entretanto, as densidades volumétricas desses capins foram, praticamente, o dobro da registrada para o capim-piatã. As DVMS variaram de 211 a $184 \mathrm{~kg} \mathrm{ha}^{-1}$ por $\mathrm{cm}$, para o capim-xaraés (Carloto et al., 2011), e de 220 a 185 para o capim-marandu (Paula, 2010). As diferenças na arquitetura do dossel destas três cultivares de $U$. brizantha são bem visíveis no campo. O capim-piatã apresenta crescimento mais ereto em relação ao capim-marandu, e os colmos são bem mais finos quando comparado ao capim-xaraés. A interceptação de luz pelo dossel e a massa de forragem dos pastos manejados com 15, 30 e $45 \mathrm{~cm}$ foram, respectivamente, de 52, 62 e 68\% (Nantes, 2011), e de 1,9, 3,3 e 4,2 $\mathrm{Mg} \mathrm{ha}^{-1}$ de MS para o capim-piatã; de 53, 77 e $82 \%$, e de 2,6, 5,9 e 7,7 $\mathrm{Mg} \mathrm{ha}^{-1}$ de MS para o capim-xaraés (Carloto, 2010); e de 58, 81 e 88\%, e de 3,1, 6,1 e 7,8 $\mathrm{Mg} \mathrm{ha}^{-1}$ de MS para o capim-marandu (Paula, 2010).

A PM foi maior para o pasto manejado a $15 \mathrm{~cm}$ quando comparado aos manejados nas demais alturas (Tabela 2). Porém, a RFNF ( $\mathrm{p}=0,3588$, média $=0,47 \pm 0,04)$ foi semelhante entre os pastos manejados com diferentes intensidades de pastejo. Em geral, têm-se observado alto acúmulo de material morto (de 40 a $60 \%$ da massa de forragem) e, como consequência, baixa RFNF para os capins marandu, xaraés e piatã, sob lotação contínua (Euclides et al., 2008; Flores et al., 2008; Carloto et al., 2011).

Tabela 3. Médias e seus erros-padrão (EPM) para percentagens de colmo, em pastos de capim-piatã submetidos a três alturas de pastejo, de acordo com as estações do ano ${ }^{(1)}$.

\begin{tabular}{lccccc}
\hline Estação & \multicolumn{3}{c}{ Altura do dossel $(\mathrm{cm})$} & \multirow{2}{*}{ EPM } & Média \\
\cline { 2 - 4 } & 15 & 30 & 45 & & \\
\hline Verão & $22,1 \mathrm{bA}$ & $28,7 \mathrm{bA}$ & $39,1 \mathrm{aA}$ & 1,6 & 28,9 \\
Outono & $20,0 \mathrm{aA}$ & $27,1 \mathrm{aA}$ & $22,9 \mathrm{aB}$ & 2,0 & 25,3 \\
Primavera & $22,4 \mathrm{aA}$ & $25,0 \mathrm{aA}$ & $26,6 \mathrm{aB}$ & 1,4 & 30,1 \\
\hline Média & 21,5 & 27,0 & 29,6 & 0,7 & \\
\hline
\end{tabular}

${ }^{(1)}$ Médias seguidas de letras iguais, minúsculas nas linhas e maiúsculas nas colunas, não diferem pelo teste de Tukey, a $5 \%$ de probabilidade.
A PC foi semelhante entre os pastos manejados com diferentes intensidades de pastejo, exceto no verão quando o pasto manejado a $45 \mathrm{~cm}$ apresentou maior $\mathrm{PC}$ do que aqueles manejados a 30 e $15 \mathrm{~cm}$ (Tabela 3). Uma vez que o alongamento do colmo geralmente ocorre concomitantemente ao florescimento (Euclides et al., 2008) e que o capim-piatã apresenta florescimento precoce, em dias longos de verão, o aumento na intensidade de pastejo controlou a produção de colmo e, consequentemente, a estrutura do dossel, durante o verão. Contudo, as outras cultivares de U. brizantha (Marandu e Xaraés) têm apresentado capacidade adaptativa de alongar o entrenó, em pastos mantidos mais altos, para que a nova folha possa alcançar o topo do dossel, o que garante maior interceptação da luz solar incidente. Assim, foram constatados decréscimos na PC à medida que decresceu a altura do dossel para essas cultivares manejadas entre 15 e $45 \mathrm{~cm}$ (Paula, 2010; Carloto et al., 2011). A RFC foi menor para o pasto manejado a $45 \mathrm{~cm}$ do que para aqueles manejados nas demais alturas (Tabela 2).

Quanto às variáveis associadas ao valor nutritivo da forragem, não foi observada interação $(p=0,5825)$ entre os efeitos de altura do dossel e estação do ano. Também não houve efeito da altura de manejo para os teores de proteína bruta (PB; $\mathrm{p}=0,2716$ ), fibra em detergente neutro (FDN; $p=0,7623)$, lignina em detergente ácido (LDA; $p=0,2555)$ e digestibilidade in vitro da matéria orgânica (DIVMO; $\mathrm{p}=0,2724)$, com médias e erros-padrão de $10,7 \pm 0,6 \%$, $73,7 \pm 0,7 \%, 2,9 \pm 0,1 \%$, e $61,1 \pm 1,3 \%$, respectivamente, para os teores de PB, FDN, LDA e DIVMO. É provável que a semelhança no valor nutritivo entre os pastos manejados com diferentes alturas tenha sido resultante da semelhança na PF em seus dosséis.

Não foi observada interação entre os efeitos de altura do dossel e estação do ano para a taxa de lotação (TL; $\mathrm{p}=0,6731$ ), nem para as ofertas de matéria seca

Tabela 4. Médias, seus erros-padrão (EPM) e nível de significância (p) para ofertas de matéria seca (OMS) e de lâmina foliar (OF), taxa de lotação (TL) e ganho por área (GA), em pastos de capim-piatã submetidos a três alturas de pastejo ${ }^{(1)}$.

\begin{tabular}{lccccc}
\hline Característica & \multicolumn{3}{c}{ Altura $(\mathrm{cm})$} & \multirow{2}{*}{ EPM } & $\mathrm{p}$ \\
\cline { 2 - 5 } & 15 & 30 & 45 & \\
\hline OMS (kg de forragem por 100 kg de PV) & $7,9 \mathrm{~b}$ & $13,5 \mathrm{a}$ & $17,0 \mathrm{a}$ & 1,3 & 0,0005 \\
OF (kg de forragem por 100 kg de PV) & $3,6 \mathrm{~b}$ & $4,9 \mathrm{ab}$ & $7,2 \mathrm{a}$ & 0,8 & 0,0141 \\
TL (UA ha-1) & $3,8 \mathrm{a}$ & $3,1 \mathrm{ab}$ & $2,4 \mathrm{~b}$ & 0,4 & 0,0459 \\
GA (kg PV ha-1 por período das águas) & $1.050 \mathrm{a}$ & $910 \mathrm{a}$ & $635 \mathrm{~b}$ & 30 & 0,0209 \\
\hline${ }^{(1)}$ Médias seguidas de letras iguais não diferem pelo teste de Tukey, a 5\% \\
de probabilidade.
\end{tabular}


(OMS; $p=0,3767)$ e de folhas (OF; $p=0,1616)$. Quanto às ofertas ( $\mathrm{kg}$ de $\mathrm{MS}$ por $100 \mathrm{~kg}$ de $\mathrm{PV})$, houve decréscimos na OMS e na OF à medida que aumentou a intensidade de pastejo (Tabela 4). A redução nas ofertas de forragem, provavelmente, foi decorrente dos acréscimos nas taxas de lotação utilizadas para manter as alturas pré-estabelecidas, uma vez que não houve diferenças nas taxas de crescimento da planta $\left(\mathrm{p}=0,5618\right.$; média $=67,3 \pm 6,4 \mathrm{~kg} \mathrm{ha}^{-1}$ por dia de MS) e de acúmulo de lâminas foliares (TAF; $\mathrm{p}=0,6738$; média $=35,5 \pm 5,4 \mathrm{~kg} \mathrm{ha}^{-1}$ por dia de MS) entre os pastos manejados nas diferentes alturas. Este fato pode ser explicado pela compensação entre tamanho e densidade de perfilhos em comunidades de plantas (Sbrissia \& Da Silva, 2008). Essa compensação pode fazer com que grandes variações entre regimes de desfolhação resultem em apenas pequenas diferenças no acúmulo de forragem.

Os animais nos pastos com diferentes alturas de dossel apresentaram ganhos médios diários semelhantes $(\mathrm{p}=0,5920)$, e a média e o seu o erro-padrão foram de $650 \pm 47 \mathrm{~g}$ por novilho. Este ganho foi inferior ao de $770 \mathrm{~g}$ por novilho obtido por Euclides et al. (2009), em pasto de capim-piatã, sob lotação contínua, durante três períodos das águas. O menor desempenho encontrado no presente trabalho não pode ser atribuído ao valor nutritivo, uma vez que os teores médios de $\mathrm{PB}$ e DIVMO registrados foram superiores $(10,7$ e $61,1 \%)$ aos reportados por Euclides et al. (2009), que foram, respectivamente, 8,8 e $55,3 \%$.

A seleção da dieta é o principal fator do processo que influencia a condição nutricional do animal (Walker, 1995). Assim, variações no processo de pastejo, decorrentes das modificações na estrutura do dossel, podem influenciar, de forma relevante, o consumo de forragem e, consequentemente, a produção animal. Palhano et al. (2007) e Trindade et al. (2007) demonstraram que a estrutura do dossel foi mais importante do que o valor nutritivo no controle do consumo de forragem pelos animais pastejando gramíneas tropicais. O pasto manejado a $45 \mathrm{~cm}$ apresentou menores RFC e DVMS, quando comparado aos manejados a 30 e $15 \mathrm{~cm}$ (Tabela 2), ou seja, uma estrutura do dossel desfavorável ao pastejo seletivo, provavelmente responsável pela limitação do ganho de peso neste pasto.

Por sua vez, o desempenho animal está relacionado à oferta de forragem (Hodgson, 1990). Machado et al. (2008) encontraram relação assintótica entre a oferta de lâminas foliares e o desempenho animal, tendo obtido GMD de, aproximadamente, $800 \mathrm{~g}$ por animal, com uma OF de $8 \mathrm{~kg}$ de folha por $100 \mathrm{~kg}$ de $\mathrm{PV}$, em pasto de capim-marandu. O GMD reportado por Euclides et al. (2009) foi obtido com uma oferta de $7,8 \mathrm{~kg}$ de folha por $100 \mathrm{~kg}$ de PV. No presente trabalho, os pastos manejados com 15 e $30 \mathrm{~cm}$ apresentaram OF menores do que o manejado a $45 \mathrm{~cm}$ (Tabela 4). Assim, nestes pastos, o limitante da ingestão de forragem pode ter sido a $\mathrm{OF}$, que foi de 3,6 e 4,9 $\mathrm{kg}$ de folha por $100 \mathrm{~kg}$ de PV, respectivamente, para os pastos com 15 e $30 \mathrm{~cm}$. Carloto et al. (2011) observaram que o GMD de animais pastejando o capim-xaraés foi limitado quando a OF foi de 5,5 $\mathrm{kg}$ de folhas por $100 \mathrm{~kg}$ de PV.

Para manter as alturas pré-estabelecidas, houve um acréscimo na taxa de lotação (TL) à medida que se aumentou a intensidade de pastejo (Tabela 4). Foram observados maiores ganhos de pesos por área (GPA) nos pastos manejados com 15 e $30 \mathrm{~cm}$. O GPA obtido no pasto com $45 \mathrm{~cm}$ de altura foi semelhante à média de três anos (600 kg PV ha ${ }^{-1}$ no período das águas), verificada por Euclides et al. (2009), em pasto de capim-piatã; no entanto, este ganho foi muito inferior aos obtidos, no presente trabalho, com os pastos manejados a 15 e $30 \mathrm{~cm}$ (Tabela 4). Isso indica que o pasto de capim-piatã pode ser manejado mais baixo sem prejuízo para a produção do animal, o que resulta em melhor aproveitamento da forragem produzida.

Todas as variáveis associadas ao valor nutritivo foram semelhantes $(\mathrm{p}=0,0581)$ ao longo do período experimental. Também não houve diferença entre as estações do ano para PF $(\mathrm{p}=0,1335)$ e RFNF ( $p=0,1352)$. Contudo, a taxa de acúmulo de folhas (TAF) foi maior durante o verão quando comparado às demais estações (Tabela 5). Isso pode ser explicado pelas condições meteorológicas (Figuras 1 A e B) e pelas adubações de manutenção realizadas nesta estação, o que promoveu condições favoráveis ao desenvolvimento da planta. Já no outono, a baixa TAF foi consequência do deficit hídrico registrado durante toda a estação (Figura 1 $\mathrm{B}$ ), associado à queda de temperatura (Figura $1 \mathrm{~A}$ ). Mesmo com o decréscimo na TL (Tabela 5), para ajustar esta situação, a MST, a MSF e a DVMS foram menores do que as observadas para as outras estações. Durante a primavera, houve aumento da radiação e da temperatura (Figura $1 \mathrm{~A}$ ); porém, a precipitação foi 
Tabela 5. Médias e nível de significância (p) para taxa de acúmulo de lâmina foliar (TAF), massas de matéria seca (MST) e de lâmina foliar (MSF), densidade volumétrica de matéria seca (DVMS), relação folha:colmo (RFC), percentagem de material morto $(\mathrm{PM})$ e taxa de lotação (TL), em pastos de capim-piatã submetidos a três alturas de pastejo, de acordo com a estação do ano ${ }^{(1)}$.

\begin{tabular}{|c|c|c|c|c|}
\hline \multirow[t]{2}{*}{ Características } & \multicolumn{3}{|c|}{ Estação do ano } & \multirow[t]{2}{*}{$\mathrm{p}$} \\
\hline & Verão & Outono & Primavera & \\
\hline TAF $\left(\mathrm{kg} \mathrm{ha}^{-1}\right.$ por dia de MS) & $48,4 a(5,1)$ & $25,6 \mathrm{~b}(6,3)$ & $30,7 \mathrm{~b}(4,5)$ & 0,0128 \\
\hline $\operatorname{MST}\left(\mathrm{kg} \mathrm{ha}^{-1}\right.$ de MS) & $3.210 \mathrm{a}(109)$ & $2.760 \mathrm{~b}(134)$ & $3.360 \mathrm{a}(95)$ & 0,0031 \\
\hline $\operatorname{MSF}\left(\mathrm{kg} \mathrm{ha}^{-1}\right.$ de MS) & $1.085 \mathrm{a}(72)$ & $770 \mathrm{~b}(88)$ & $1.090 \mathrm{a}(63)$ & 0,0127 \\
\hline DVMS ( $\mathrm{kg} \mathrm{ha}^{-1} \mathrm{~cm}$ de MS) & $114 \mathrm{a}(3,8)$ & $99 b(4,7)$ & $113 \mathrm{a}(3,3)$ & 0,0269 \\
\hline RFC & $1,2 \mathrm{ab}(0,07)$ & $1,1 \mathrm{~b}(0,08)$ & $1,4 \mathrm{a}(0,06)$ & 0,0484 \\
\hline PM (\%) & $38,5 \mathrm{~b}(1,5)$ & $46,5 \mathrm{a}(1,8)$ & $45,2 \mathrm{a}(1,2)$ & 0,0016 \\
\hline TL $\left(\mathrm{UA} \mathrm{ha}^{-1}\right)$ & $4,82 \mathrm{a}(0,36)$ & $1,49 \mathrm{c}(0,51)$ & $2,95 \mathrm{~b}(0,29)$ & 0,0001 \\
\hline
\end{tabular}

(1)Médias seguidas de letras iguais não diferem pelo teste de Tukey, a 5\% de probabilidade. Valores entre parênteses representam o erro-padrão da média.

insuficiente para resolver o deficit hídrico do solo no início desta estação, em setembro e outubro (Figura 1 B), condição relacionada à senescência da folha e à morte dos perfilhos (Cano et al., 2004; Mesquita et al., 2010), o que resultou em baixa TAF no início da primavera (Tabela 1). Apesar da alta TAF observada em novembro e dezembro, a média durante a primavera foi igual à do outono (Tabela 5). Ressalta-se que, nesta estação, a TL utilizada foi adequada, o que manteve a MST, a MSF e a DVMS semelhantes às observadas no verão.

A RFC foi menor no outono, intermediária no verão e maior durante a primavera. Já a PM, foi menor no verão quando comparado às demais estações (Tabela 5). Os fatores limitantes de crescimento da planta, descritos acima, foram os principais responsáveis pela variação na estrutura do dossel ao longo do período experimental.

A variação na TL ao longo do ano seguiu o padrão de variação da TAF. A OF foi semelhante $(p=0,2520)$ entre as estações do ano, o que sugere que o ajuste da taxa de lotação foi adequado ao longo do ano.

\section{Conclusões}

1. O capim-piatã apresenta grande flexibilidade de manejo sob lotação contínua e pode ser manejado entre 15 e $45 \mathrm{~cm}$ de altura.

2. Para a melhor utilização da forragem produzida, o capim-piatã, sob lotação contínua, deve ser manejado entre 15 e $30 \mathrm{~cm}$ de altura, sem prejuízo para a produção animal.

\section{Agradecimentos}

À Fundação de Apoio ao Desenvolvimento do Ensino, Ciência e Tecnologia do Estado de Mato Grosso do Sul, à Embrapa Gado de Corte e ao Conselho Nacional de Desenvolvimento Científico e Tecnológico ( $\mathrm{CNPq})$, pelo apoio financeiro e pela concessão de bolsas.

\section{Referências}

BRASIL. Ministério da Agricultura, Pecuária e Abastecimento. Instrução Normativa $n^{\circ} 23$, de 30 de julho de 2008. Estabelece os requisitos mínimos a serem observados na realização de ensaios de Valor de Cultivo e Uso (VCU) de cultivares das seguintes espécies de gramíneas forrageiras: Brachiaria brizantha (Hochst. ex A. Rich.) Stapf; Brachiaria decumbens Stapf; Brachiaria dictyoneura (Fig. et De Not) Stapf; Brachiaria humidicola (Rendle) Schweick.; Brachiaria ruziziensis R.Germ. \& C.M.Evrard; Panicum maximum Jacq.; Pennisetum purpureum Schumach.; híbridos e populações resultantes de cruzamentos interespecíficos. Diário Oficial [da] República Federativa do Brasil, 1 ago. 2008. Seção 1, p.12.

CALVANO, M.P.C.A.; EUCLIDES, V.P.B.; MONTAGNER, D.B.; LEMPP, B.; DIFANTE, G. dos S.; FLORES, R.S.; GALBEIRO, S. Tillering and forage accumulation in Marandu grass under different grazing intensities. Revista Ceres, v.58, p.781-789, 2011. DOI: 10.1590/S0034-737X2011000600015.

CANO, C.C.P.; CECATO, U.; CANTO, W.V. do; RODRIGUES, A.B.; JOBIM, C.C.; RODRIGUES, A.M.; GALBEIRO, S.; NASCIMENTO, W.G. do. Produção de forragem do capim-tanzânia (Panicum maximum Jacq. cv. Tanzânia-1) pastejado em diferentes alturas. Revista Brasileira de Zootecnia, v.33, p.1949-1958, 2004. DOI: $10.1590 / \mathrm{S} 1516-35982004000800005$.

CARLOTO, M.N. Características morfogênicas, acúmulo e qualidade da forragem do capim-xaraés submetido a intensidades de pastejo sob lotação contínua. 2010. 70p. Dissertação (Mestrado) - Universidade Federal do Mato Grosso do Sul, Campo Grande.

CARLOTO, M.N.; EUCLIDES, V.P.B.; MONTAGNER, D.B.; LEMPP, B.; DIFANTE, G. dos S.; PAULA, C.C.L. de. Desempenho animal e características de pasto de capim-xaraés sob diferentes intensidades de pastejo, durante o período das águas. Pesquisa Agropecuária Brasileira, v.46, p.97-104, 2011. DOI: 10.1590/ S0100-204X2011000100013

CARNEVALLI, R.A.; DA SILVA, S.C.; CARVALHO, C.A.B de; SBRISSIA, A.F.; FAGUNDES, J.L.; PINTO, L.F. de M.; PEDREIRA, C.G.S. Desempenho de ovinos e respostas de pastagens de Coastcross submetidas a regimes de desfolha sob lotação contínua. Pesquisa Agropecuária Brasileira, v.36, p.919-927, 2001a. DOI: 10.1590/S0100-204X2001000600010. 
CARNEVALLI, R.A.F.; DA SILVA, S.C.; FAGUNDES, J.L.; SBRISSIA, A.F.; CARVALHO, C.A.B. de; PINTO, L.F. de M.; PEDREIRA, C.G.S. Desempenho de ovinos e respostas de pastagens de Tifton-85 (Cynodon spp.) sob lotação contínua. Scientia Agricola, v.58, p.7-15, 2001b. DOI: 10.1590/ S0103-90162001000100002.

DA SILVA, S.C.; CARVALHO, P.C.F. Foraging behaviour and intake in the favourable tropics/sub-tropics. In: MCGILLOWAY, D.A. (Ed.). Grassland: a global resource. Dublin: Wageningen Academic, 2005. p.81-95.

DIFANTE, G. dos S.; EUCLIDES, V.P.B.; NASCIMENTO JÚNIOR, D. do; DA SILVA, S.C. da; TORRES JUNIOR, R.A. de A.; SARMENTO, D.O. de L. Ingestive behaviour, herbage intake and grazing efficiency of beef cattle steers on Tanzania guineagrass subjected to rotational stocking managements. Revista Brasileira de Zootecnia, v.38, p.1001-1008, 2009. DOI: 10.1590/ S1516-35982009000600005.

EUCLIDES, V.P.B. Alternativas para intensificação da produção de carne bovina em pastagem. Campo Grande: Embrapa Gado de Corte, 2000. 65p.

EUCLIDES, V.P.B.; MACEDO, M.C.M.; VALLE, C.B. do; BARBOSA, R.A.; GONÇALVES, W.V. Produção de forragem e características da estrutura do dossel de cultivares de Brachiaria brizantha sob pastejo. Pesquisa Agropecuária Brasileira, v.43, p.1805-1812, 2008. DOI: 10.1590/S0100-204X2008001200023.

EUCLIDES, V.P.B.; MACEDO, M.C.M.; VALLE, C.B. do; DIFANTE, G.S.; BARBOSA, R.A.; CACERE, E.R. Valor nutritivo da forragem e produção animal em pastagens de Brachiaria brizantha. Pesquisa Agropecuária Brasileira, v.44, p.98-106, 2009. DOI: $10.1590 / \mathrm{S} 0100-204 X 2009000100014$.

FLORES, R.S.; EUCLIDES, V.P.B.; ABRÃO, M.P.C.; GALBEIRO, S.; DIFANTE, G. dos S.; BARBOSA, R.A. Desempenho animal, produção de forragem e características estruturais dos capins marandu e xaraés submetidos a intensidades de pastejo. Revista Brasileira de Zootecnia, v.37, p.1355-1365, 2008. DOI: 10.1590/ S1516-35982008000800004.

HODGSON, J. Grazing management - science into practice. New York: John Wiley, 1990. 203p.

LITTELL, R.C.; HENRY, P.R.; AMMERMAN, C.B. Statistical analysis of repeated measures data using SAS procedures. Journal of Animal Science, v.76, p.1216-1231, 1998.

MACHADO, L.A.Z.; FABRÍCIO, A.C.; GOMES, A.; ASSIS, P.G.G.; LEMPP, B.; MARASCHIN, G.E. Desempenho de animais alimentados com lâminas foliares em pastagem de capim-marandu. Pesquisa Agropecuária Brasileira, v.43, p.1609-1616, 2008. DOI: 10.1590/S0100-204X2008001100021.

MARTEN, G.C.; SHENK, J.S.; BARTON II, F.E. Near-infrared reflectance spectroscopy (NIRS): analysis of forage quality.
Washington: USDA, 1985. 110p. (USDA. Agriculture handbook, 643).

MESQUITA, P. de; DA SILVA, S.C.; PAIVA, A.J.; CAMINHA, F.O.; PEREIRA, L.E.T.; GUARDA, V.D.; NASCIMENTO JÚNIOR, D. do. Structural characteristics of marandu palisade grass swards subjected to continuous stocking and contrasting rhythms of growth. Scientia Agricola, v.67, p.23-30, 2010. DOI: 10.1590/S0103-90162010000100004.

NANTES, N.N. Acúmulo de forragem, características morfogênicas e estruturais de pastos de capim-piatã sob lotação continua. 2011. 63p. Dissertação (Mestrado) - Universidade Federal do Mato Grosso do Sul, Campo Grande.

PALHANO, A.L.; CARVALHO, P.C. de F.; DITTRICH, J.R.; MORAES, A. de; DA SILVA, S.C.; MONTEIRO, A.L.G. Características do processo de ingestão de forragem por novilhas holandesas em pastagem de capim-mombaça. Revista Brasileira de Zootecnia, v.36, p.1014-1021, 2007. DOI: 10.1590/ S1516-35982007000500005.

PAULA, C.C.L. Características morfogênicas, acúmulo e qualidade da forragem do capim-marandu submetido à intensidades de pastejo sob lotação contínua. 2010. 39p. Dissertação (Mestrado) - Universidade Federal do Mato Grosso do Sul, Campo Grande.

PETERSEN, R.G.; LUCAS JUNIOR, H.L. Computing methods for the evaluation of pastures by means of animal response. Agronomy Journal, v.60, p.682-687, 1968. DOI: 10.2134/agron j1968.00021962006000060031x.

SANTOS, H.G. dos; JACOMINE, P.K.T.; ANJOS, L.H.C. dos; OLIVEIRA, V.A. de; OLIVEIRA, J.B. de; COELHO, M.R.; LUMBRERAS, J.F.; CUNHA, T.J.F. (Ed.). Sistema brasileiro de classificação de solos. 2.ed. Rio de Janeiro: Embrapa Solos, 2006. $316 \mathrm{p}$.

SAS INSTITUTE. User software: changes and enhancements through release. Version 6.11. Cary: SAS Institute, 1996.

SBRISSIA, A.F.; DA SILVA, S.C. Compensação tamanho/ densidade populacional de perfilhos em pastos de capim-marandu. Revista Brasileira de Zootecnia, v.37, p.35-47, 2008. DOI: 10.1590/S1516-35982008000100005.

TRINDADE, J.K. da; DA SILVA, S.C.; SOUZA JÚNIOR, S.J. de; GIACOMINI, A.A.; ZEFERINO, C.V.; GUARDA, V. Del A.; CARVALHO, P.C. de F. Composição morfológica da forragem consumida por bovinos de corte durante o rebaixamento do capim-marandu submetido a estratégias de pastejo rotativo. Pesquisa Agropecuária Brasileira, v.42, p.883-890, 2007. DOI: 10.1590/S0100-204X2007000600016.

WALKER, J.W. Viewpoint: grazing management and research now and in the next millennium. Journal of Range Management, v.48, p.350-357, 1995. DOI: 10.2307/4002488.

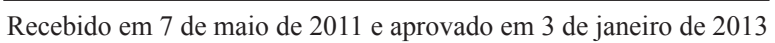

